tional age to full development, no unequivocal conclusions can be made concerning structure and function in the tight junctions of the choroid plexus from the recorded observations.

\section{W. Bradbury}

Department of Physiology,

King's College,

Strand,

London WC2, UK

${ }^{1}$ Møllgård, K., Malinowska D. H. \& Saunders, N. R. Nature 264, 293-294 (1976)

Bradbury, M. W. B. et al, J. Physiol., Lond. 227, 591-619 (1972).

3 Evans, C. A. N., Reynolds, J. M., Reynolds, M. L., Saunders, N. R. \& Segal, M. B. J. Physiol., Lond. 238, 371-386 (1974). Dziegielewska, K. M. et al. J. Physiol., Lond. 258,
86P-87P (1976).

Møllgard et al. REPLY-We thank Dr Bradbury for raising an important aspect of the interpretation of our work which was insufficiently dealt with in our letter because of lack of space. In parallel with our studies of the choroid plexus and cerebrospinal fluid (CSF) we have also studied the ultrastructure of cerebral vessels and penetration of the same markers (nonelectrolyte and plasma proteins) into developing brain. We have previously published results of uitrastructural studies of vessels in the immature brain $^{1}$. These results, although preliminary, suggested that interendothelial cell tight junctions develop very early in gestation. This has recently been confirmed (unpublished observations) in sheep brain as early as $30 \mathrm{~d}$ gestation. The strand number seems to be greater than in the choroid plexus at all ages so far examined. It is technically more difficult to obtain freeze-fracture replicas of cerebral endothelial tight junctions, so it is doubtful if it will be possible to provide evidence for endothelia on the scale already obtained for the epithelial cells of the choroid plexus. However, all endothelial cell junctions so far examined, either by freeze-fracture or by thin section, have had the appearance of well formed tight junctions.

Our permeability data (ref. 2 and unpublished) in 60-d sheep foetuses show that there is more restriction on penetration of pratein from blood into brain than into CSF. This implies the presence of junctions which are functionally tight to protein. The data on foetal sheep electrolytes in CSF and plasma $^{3}$, mentioned by Dr Bradbury, showed that CSF-plasma gradients were present for chloride and magnesium by $60 \mathrm{~d}$ gestation. This probably indicates the presence of both the appropriate ion pumps and a permeability barrier adequate to prevent loss of the gradients. Our non-electrolyte data (ref. 44 and unpublished) suggest that inulin and sucrose penetrate into brain and CSF to a similar degree if the brain extracellular space is assumed to be equivalent to the chloride space. It may be, however, that these materials reach the brain in early development predominantly through the choroid plexus since this is disproportionately large in the immature foetus and the brain is poorly vascularised.

\section{K. Mollgard}

Institute of Medical Anatomy A, University of Copenhagen,

Universitetsparken 1,

2100 Copenhagen, Denmark

\section{H. Malinowska}

\section{N. R. SAunders}

Department of Physiology,

University College London, Gower Street, London WC1, UK

1 Møllgård, K. \& Saunders, N. R. J. Neurocytol. 4,
453-468 (1975).
2 Dziegielewska, K. M. et al. J. Physiol., Lond. 285,
86-87R (1976).
${ }^{3}$ Bradbury, M. W. B. et al. J. Physiol., Lond. 227,
591-610 (1972).
4 Evans, C. A. N., Reynolds, J. M., Reynolds, M. L.,
Saunders, N. R. \& Segal, M. B. J. Physiol., Lond.
238, 371-386 (1974).

\section{Collagen microfibrils and cell attachment proteins}

PeARLSTEIN $^{1}$, following $\mathrm{Klebe}^{2}$ in the search for a cell attachment protein (CAP) (ref. 3) between mesenchymal cells and collagen, seems to disregard the lesson learnt from Jamieson's similar work on platelets'. They omitted to examine the microfibrillar structure of their reconstituted collagen substrata $^{1-4}$. Pearlstein ${ }^{1}$ treats his collagen with $8 \mathrm{M}$ urea to minimise 'nonspecific' adhesion (see below). But he fails to note that urea inhibits fibrillogenesis ${ }^{5}$, or that collagen-binding both by platelets ${ }^{s, 6}$ and fibroblasts ${ }^{8}$ depends crucially on microfibril aggregation, which also has a key role in the adhesion of BHK cells to a microfibril-forming polysaccharide substratum $^{7,8}$

Moreover, the divalent ion requirements of CAP ${ }^{1,2}$ seem to conflict with those of other experiments ${ }^{8,10}$ which do not require CAP for adhesion to various forms of collagen. Rabinovitch and DeStefano showed that $\mathrm{Mg}$ or $\mathrm{Mn}$ by themselves promote adhesion of carcinoma cells to gelatin ${ }^{\circ}$, and I have confirmed this for BHK cells on adsorbed films of soluble collagen ${ }^{10}$.

Therefore, the fact that aggregation and divalent cations, respectively, can promote adhesion independently of
CAP calls for re-assessment of the "background" of "non-specific" adhesion (that is, in the absence of CAP) subtracted by Pearlstein ${ }^{1}$ and Klebe ${ }^{3,3}$. I suggest that their background adhesion, far from being an inconsiderable artefact, may actually represent a physiologically significant attachment of the mesenchymal cells to aggregated, microfibrillar parts of the reconstituted collagen substrata, under the influence of divalent cation alone; while their CAP-specific adhesion may be to a single-stranded (for example, urea-treated) form of collagen, not found in intact connective tissue. So far, unfortunately, CAP does not seem to have been tested on a physiologically intaot form of collagen, such as omentum.

Hence the experiments on mesenchymal cells ${ }^{1-3}$ should be repeated as those on platelets ${ }^{4}$ have been, that is, with confirmed microfibrils, ${ }^{\mathrm{s}, 6}$. Moreover, since there is evidence that various mesenchymal cells ${ }^{7,8,10-13}$ explore micro-architectural and mechanical aspects of their substrata, critical work with mesenchymal cells on collagen should also describe the size, spatial distribution and rigidity of microfibrillar particles.

\section{N. G. Maroudas}

71 Park Avenue North, London NW10, UK

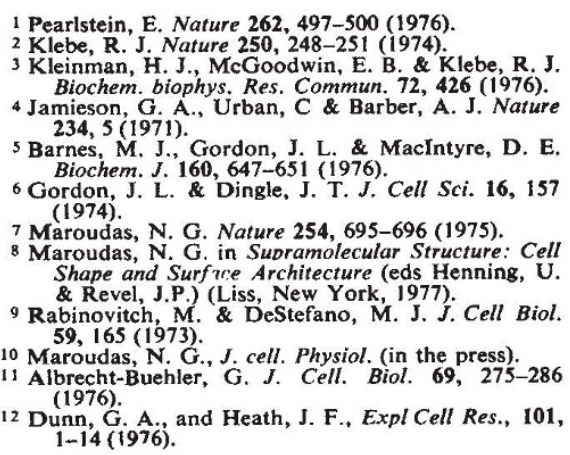

\section{Stereospecificity and clinical potency of neuroleptics}

ENNA et al. ${ }^{1}$ have drawn attention to the potential, and some of the difficulties, of studies of the stereospecificity of neuroleptic drugs in elucidating the anti-schizophrenic action of these compounds. Although they have provided new data of considerable value we feel that they have obscured one issue. There is an increasing body of evidence on the stereospecificity of these drugs in in vitro assay systems and some evidence on their effects on animal behaviours, but as far as we are aware there are no systematic studies 